\title{
Aspectos ecofisiológicos de Sinningia aghensis Chautems em condições de campo ${ }^{1}$
}

\author{
Geraldo Rogério Faustini Cuzzuol ${ }^{2,4}$ e Joscineia Kelli Clippel ${ }^{3}$
}

Recebido: 06.12.2007; aceito: 27.11.2008

\begin{abstract}
Ecophysiological aspects of Sinningia aghensis Chautens under field conditions). The effect of the seasonal variation was investigated in tubers carbohydrates concentration, biomass allocation and fotossinthetic pigments contents of the rupicolous Sinningia aghensis. The starch varied $8 \%$ of dry mass (DM) in the summer to $80 \%$ DM in the winter that was inversely correlated with the precipitation. That increase of the starch in the winter occurred to the sucrose and glucose as well as the aerial organs allocation detriment. The starch decline in the spring has been associated with the flowering stage of which reflected in the ratio aerial organs:tubers and carotenoids increase. The maintenance of the aerial organs in the winter allied to the water content leaf constant at all times of the year suggests the presence of leaf metabolic that should play the protection role against unfavorable environmental conditions such as drought.
\end{abstract}

Key words: carbohydrates, ecophysiology, Gesneriaceae, seasonality

RESUMO - (Aspectos ecofisiológicos de Sinningia aghensis Chautems em condições de campo). Foi investigado o efeito da sazonalidade na concentração de carboidratos dos tubérculos da rupestre S. aghensis bem como a alocação de biomassa e os teores dos pigmentos fotossintéticos. O amido variou entre $8 \%$ no verão a $80 \%$ da massa seca (MS) no inverno tendo sido correlacionado inversamente com a precipitação. $\mathrm{O}$ aumento do amido ocorreu em detrimento da concentração de sacarose e glicose bem como da alocação de biomassa para a parte aérea. A diminuição do amido na primavera foi associada com a fase de floração ocorrendo simultaneamente ao aumento da razão parte aérea:tubérculos e ao incremento de carotenóides. A manutenção da parte aérea no inverno aliada aos valores constantes do conteúdo relativo de água das folhas em todas as épocas do ano sugere a presença de importantes mecanismos fisiológicos com função de proteção contra as condições ambientais desfavoráveis como a restrição hídrica.

Palavras-chave: carboidratos, ecofisiologia, Gesneriaceae, sazonalidade

\section{Introdução}

O metabolismo e o crescimento vegetal estão sob influência da variação sazonal das condições ambientais como parte das estratégias adaptativas em resposta ao estresse (Lambers et al. 1998, Larcher 2000). Em algumas espécies herbáceas tuberosas tropicais brasileiras o teor de carboidratos nãoestruturais tende a aumentar nos meses frios e secos do ano (Carvalho \& Dietrich 1993, Isejima \& FigueiredoRibeiro 1993, Moraes et al.2002, Vieira \& FigueiredoRibeiro 1993). O mesmo tem sido verificado em arbóreas tropicais que apresentaram maiores teores de glicose, frutose e sacarose nos meses de estiagem (Würth et al. 2005). Já para a herbácea leguminosa
Oxytropis sericea, rupestre dos alpes do mediterrâneo, o aumento de carboidratos não-estruturais ocorreu nos meses chuvosos (Clair-Maczuljatys et al. 1994, Wyka 1999).

As variações sazonais dos carboidratos sugerem que, além do papel de reserva, esses compostos podem estar relacionados aos mecanismos adaptativos em resposta ao estresse ambiental, oferecendo resistência à baixa temperatura e/ou dessecação (Dias-Tagliacozzo et al. 1999,2004). Segundo Hendry \& Wallace (1993), a tolerância de algumas plantas ao déficit hídrico parece estar relacionada ao acúmulo de carboidratos solúveis, incluindo frutanos, além da sacarose e frutose, que funcionam como osmorreguladores.

1. Parte da Dissertação de Mestrado do segundo autor

2. Universidade Federal do Espírito Santo, Departamento de Ciências Biológicas, CCHN, Campus Universitário Alaor Queiroz de Araújo, Av. Fernando Ferrrari 514, 29075-910 Vitória, ES, Brasil

3. Programa de Pós-Graduação em Biologia Vegetal (ppgbv) da Universidade Federal do Espírito Santo

4. Autor para correspondência: gcuzzuol@gmail.com 
No Brasil, os primeiros estudos a respeito da influência das variações ambientais na concentração de carboidratos em plantas nativas tropicais tiveram início na década 90, especialmente com espécies do cerrado (Isejima et al. 1991, Carvalho \& Dietrich 1993, Isejima \& Figueiredo-Ribeiro 1993, DiasTagliacozzo et al. 1999). O ciclo fenológico de herbáceas do cerrado brasileiro é caracterizado por uma fase de crescimento vegetativo que se inicia na primavera e se estende até o final do outono, quando os órgãos aéreos entram em senescência, coincidindo com o período de baixa temperatura e precipitação. No inverno, o conteúdo de carboidratos do tipo frutanos aumenta, chegando a representar $80 \%$ da massa seca de seus órgãos subterrâneos (Carvalho \& Dietrich 1993, 1996, Vieira \& Figueiredo-Ribeiro 1993). Na primavera, esses polissacarídeos são mobilizados para a fase de rebrota que coincide, naturalmente, com o início das chuvas de setembro quando o teor de frutanos declina drasticamente.

Resultados preliminares na flora de Mata Atlântica do Espírito Santo, considerada uma das maiores diversidades do planeta (Thomaz \& Monteiro 1997), revelaram a presença de baixo conteúdo de amido em tubérculos de Sinningia aghensis Chautems (Gesneriaceae) no verão de 2003 quando esse polissacarídeo representou apenas $5 \%$ da massa seca (Clippel 2005). Essa espécie, como a maioria das espécies de Sinnignia, possui um tubérculo perene e parte aérea anual com distribuição neotropical (Chautems 1991, Chautems \& Weber 1999). Suas folhas são pecioladas e pilosas originadas de um curto caule aéreo. Na fase reprodutiva, quando ocorre a emissão da inflorescência no ápice da haste floral, a parte aérea pode alcançar, em média, $70 \mathrm{~cm}$ de altura. Seus frutos são secos e deiscentes contendo grande quantidade de sementes de $1 \mathrm{~mm}$ de comprimento.

O hábito rupestre em afloramentos rochosos de Sinningia na floresta tropical brasileira (Meirelles et al. 1999, Safford \& Martinelli 2000), aliado à manutenção da parte aérea da maioria de suas espécies em todas as épocas do ano, permitiu levantar a hipótese de que os carboidratos nos tubérculos de $S$. aghensis estejam sob influência das variações sazonais, uma vez que o clima do Espírito Santo é caracterizado pelo verão chuvoso e o inverno com estiagem (INMET 2005, figura 1). Durante os meses secos, as folhas apicais permanecem verdes com sinais de clorose e senescência nas folhas basais (Clippel 2005). O presente trabalho foi desenvolvido com o objetivo de investigar o comportamento ecofisiológico da rupestre Sinningia aghensis em resposta às variações sazonais do meio ambiente.

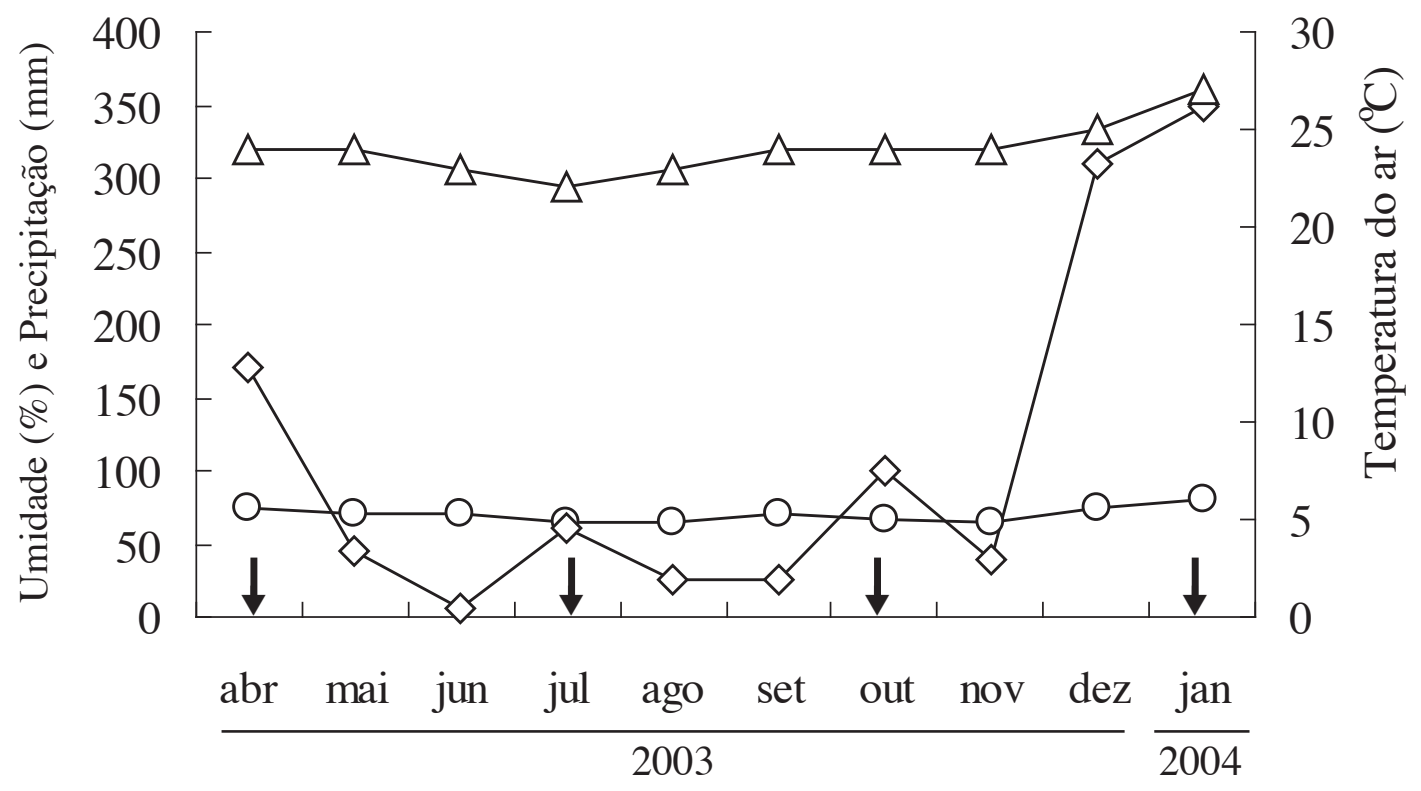

Figura 1. Variações na umidade relativa $(O$ ) e temperatura atmosférica $(\Delta)$ e da precipitação $(\diamond)$ de abril de 2003 a janeiro de 2004. As setas indicam as épocas de coletas do material biológico e das medidas em campo. Dados fornecidos pelo Instituto Nacional de Metereologia (INMET).

Figure 1. Variations in relative humidity ( $O$ ) and air temperature $(\Delta)$ and precipitation $(\diamond)$ from april 2003 to january 2004 . The arrows indicate the times of collections of biological material and measures in the field. Data provided by the "Instituto Nacional de Metereologia" (INMET). 


\section{Material e métodos}

Material vegetal - Plantas de S. aghensis Chautems (Gesneriaceae) apresentando aspectos morfológicos sadios e homogêneos foram coletadas na pedreira do Morro do Cruzeiro (150 m de altitude), município de Vila Velha (20²0'12'S, 40¹7'28”W), Espírito Santo, no outono (30 de abril de 2003), inverno (11 de julho de 2003), primavera (23 de outubro de 2003) e verão (29 de janeiro de 2004), por volta das 8:00 horas. As plantas coletadas no outono e no inverno encontravam-se na fase vegetativa, enquanto as da primavera possuíam inflorescência e as do verão, com folhas apresentando sinais de clorose e de senescência, especialmente nas folhas basais. $\mathrm{O}$ material vegetal foi acondicionado em caixas térmicas com gelo seco e conduzido ao laboratório do Setor de Botânica da Universidade Federal do Espírito Santo, distante $20 \mathrm{~km}$ do local de coleta, para as extrações e quantificações dos carboidratos. No laboratório, os tubérculos foram separados da parte aérea para as medidas de massa fresca.

Extração dos carboidratos não-estruturais - Amostras de 1 grama de massa fresca da região central dos tubérculos de seis plantas de S. aghensis foram fervidos em etanol $80 \%$ por 5 min. para inativação enzimática. Em seguida, as amostras foram maceradas no gral com pistilo e submetidas à extração dos carboidratos solúveis em banho-maria a $80{ }^{\circ} \mathrm{C}$ por $15 \mathrm{~min}$. conforme o método descrito por Carvalho et al. (1997) com algumas modificações como se segue. O extrato obtido foi centrifugado a $3.000 \mathrm{~g}$ por 15 minutos, separado o sobrenadante sendo a operação repetida mais duas vezes. O resíduo foi ressuspendido em $15 \mathrm{~mL}$ de água destilada, aquecido em banho-maria $60{ }^{\circ} \mathrm{C}$ por $30 \mathrm{~min}$. e filtrado a vácuo. Repetiu-se essa operação mais uma vez. As frações etanólica e aquosa foram reunidas, concentradas em rotoevaporador $\left(60^{\circ} \mathrm{C}\right)$ e os extratos brutos armazenados em freezer a $-10{ }^{\circ} \mathrm{C}$. $\mathrm{O}$ amido foi extraído da massa residual segundo McCready et al. (1950) adicionando-se $5 \mathrm{~mL}$ de água destilada e $6,5 \mathrm{~mL}$ de ácido perclórico $52 \%$, por $15 \mathrm{~min}$. a $5 \mathrm{oC}$, em constante homogeneização. Em seguida, foram acrescentados $15 \mathrm{~mL}$ de água centrifugando-se a $3.000 \mathrm{~g}$ por $15 \mathrm{~min}$. O sobrenadante foi separado e a operação repetida mais uma vez.

Quantificação dos carboidratos não-estruturais - Foi empregado o método do fenol-sulfúrico (Dubois et al. 1956) para determinação da concentração de açúcares totais solúveis, sendo a leitura realizada em espectrofotômetro no $\lambda=620 \mathrm{~nm}$, utilizandose como padrão alíquotas de glicose de 0 a $50 \mu \mathrm{g}$. Para o conteúdo da sacarose adotou-se o método descrito por Riazi et al. (1985) que consiste na fervura da amostra por 5 minutos com hidróxido

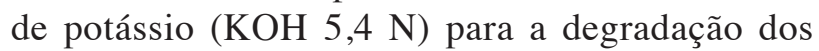
carboidratos redutores e leitura realizada a $620 \mathrm{~nm}$. A frutose livre e combinada, presente nos extratos, foi estimada após reação de hidrólise ácida em antrona $(0,2 \%)$ em $76 \%$ de ácido sulfúrico em banho-maria $\left(37^{\circ} \mathrm{C}\right)$ por $45 \mathrm{~min}$. (Jermyn 1956). Utilizou-se alíquotas de frutose de 0 a $50 \mu \mathrm{g}$ como padrão e as leituras das absorbâncias realizadas em espectrofotômetro no $\lambda=620 \mathrm{~nm}$. A concentração de glicose na forma livre presente nos extratos foi estimado pelo método enzimático (kit da BioSystem) em incubação à $25^{\circ} \mathrm{C}$ por $5 \mathrm{~min}$. e posterior leitura das absorbâncias no $\lambda=500 \mathrm{~nm}$. A reação consiste na ação da glucose oxidase e peroxidase sobre os reagentes glicose e aminoantipirina + fenol $(1 \mathrm{~mL})$, respectivamente, liberando quinonaimina usandose com padrão solução de $10 \mu 1$ de glucose/uréia/ creatina. $\mathrm{O}$ amido foi quantificado pela reação da antrona (Jermyn 1956) e a leitura das absorbâncias realizada em espectrofotômetro, no $\lambda=620 \mathrm{~nm}$ utilizando-se alíquotas de glicose de 0 a $50 \mu \mathrm{g}$ com padrão e o valor obtido em equivalentes de glicose foi multiplicado pelo fator de correção 0,9 conforme McCready et al. (1950).

Medidas de crescimento - Amostras de $1 \mathrm{~g}$ de massa fresca dos tubérculos de seis plantas foram mantidas em estufa $\left(60^{\circ} \mathrm{C}\right)$ até a estabilização da massa seca para determinação do valor de massa seca por unidade de massa fresca dos tubérculos. As folhas foram pesadas e acondicionados em estufa $\left(60^{\circ} \mathrm{C}\right)$ para obtenção da massa seca. O conteúdo de água (C.A.\%) das folhas e dos tubérculos foi determinado aplicando-se a equação C.A. = [(MF-MS)x100\%]/ MF (Lambers \& Poorter 1992) onde MF = massa fresca e MS = massa seca nas diferentes coletas. Também foi determinada a alocação de biomassa que representa a fração de matéria seca dos órgãos vegetais (Marcelis 1996).

Pigmentos fotossintéticos - Da folha apical mais expandida das seis plantas utilizadas para análise de carboidratos e das medidas de crescimento, e em boas condições morfológicas e fisiológicas, foram extraídos as clorofilas $a$ e $b$ e os carotenóides de discos foliares $\left(0,6 \mathrm{~cm}^{2}\right)$ em acetona $80 \%$ (Arnon 1949). As concentrações dos pigmentos foram estimadas pelas equações de Hendry \& Grime (1993) onde 
$V$ corresponde ao volume do extrato $(10 \mathrm{~mL})$ e $M$ representa a massa fresca foliar utilizada:

Clorofila $a=12,7 \mathrm{~A}_{663}-2,69 \mathrm{~A}_{645} \cdot \mathrm{V} / 1000 \mathrm{M}$

Clorofila $b=22,9 \mathrm{~A}_{645}-4,68_{663} . \mathrm{V} / 1000 \mathrm{M}$

Clorofila $a+b=8,02 \mathrm{~A}_{663}+20,21 \mathrm{~A}_{645} \cdot \mathrm{V} / 1000 \mathrm{M}$

Carotenóides $=\left(\mathrm{A}_{480}+0,114 \mathrm{~A}_{663}\right) *\left(\mathrm{~A}_{663}-0,638_{645}\right) \cdot \mathrm{V} / 1000 \mathrm{M}$

Análise estatística - Os dados foram submetidos à análise de variância, sendo todo e qualquer contraste entre as médias $(n=6)$ avaliado pelo teste de Tukey, em nível de 5\% de probabilidade, utilizando-se o pacote estatístico ASSISTAT (Silva \& Azevedo 2007). Em adição, foi utilizada a estatística descritiva.

\section{Resultados}

Com relação aos dados climáticos (figura 1), a precipitação apresentou sensível variação de abril de 2003 a janeiro de 2004. Nesse período o clima foi caracterizado por inverno seco onde foi registrada a menor precipitação $(60 \mathrm{~mm})$ no mês de julho. Na primavera foi registrada uma elevação da precipitação $(110 \mathrm{~mm})$ no mês de outubro enquanto maiores precipitações ocorreram no início outono $(170 \mathrm{~mm})$ em abril de 2003 e no verão $(340 \mathrm{~mm})$ em janeiro de 2004. No inverno houve ligeiro declínio da temperatura, porém, os valores foram constantes no período experimental variando de 25 a $28{ }^{\circ} \mathrm{C}$. Comportamento similar também foi verificado para a umidade relativa da atmosfera cuja amplitude foi de $70 \%$ a $80 \%$ entre outono de 2003 e verão de 2004.

Todos os carboidratos analisados mostraram variação sazonal nos tubérculos de S. aghensis. O teor dos carboidratos totais não-estruturais foi baixo não ultrapassando ao valor de $20 \%$ da massa seca declinando do outono para o inverno e aumentando da primavera para o verão (tabela 1). Comportamento similar também foi observado para a concentração de sacarose que variou de $49 \mathrm{mg} \mathrm{g}^{-1}$ no inverno para $134 \mathrm{mg} \mathrm{g}^{-1}$ de MS no verão. Dos carboidratos não-estruturais, esse dissacarídeo representou a maior fração, seguida de frutose e glicose. A frutose mostrou menor flutuação sazonal, com valor médio de $20 \mathrm{mg}$ $\mathrm{g}^{-1}$ no outono, inverno e primavera. Um aumento desse açúcar redutor foi registrado no verão aproximando-se do valor de $30 \mathrm{mg} \mathrm{g}^{-1}$. Diferente do comportamento descrito para a sacarose e frutose, a concentração de glicose, além de declinar no inverno, alcançou os mais baixos valores na primavera e verão. Dessa forma, a concentração de glicose variou de $13 \mathrm{mg} \mathrm{g}^{-1}$ no outono para o valor médio de $0,5 \mathrm{mg} \mathrm{g}^{-1}$ entre a primavera e $\mathrm{o}$ verão. Valores intermediários foram verificados no inverno quando a concentração desse monossacarídeo foi de $5 \mathrm{mg} \mathrm{g}^{-1}$. Com relação à variação na concentração dos carboidratos armazenados nos tubérculos de $S$. aghensis, o amido foi o carboidrato que apresentou variações mais representativas e maior amplitude sazonal (tabela 1). Nesse aspecto, o teor desse polissacarídeo ficou abaixo de $90 \mathrm{mg} \mathrm{g}^{-1}$ de MS no outono, primavera e verão aumentando, expressivamente, para $777 \mathrm{mg} \mathrm{g-1}$ no inverno mostrando relação inversa com os dados de precipitação (figura 1)

Os parâmetros de crescimento são apresentados na tabela 2. Embora as plantas amostradas foram escolhidas aleatoriamente de uma população nativa heterogênea quanto à idade e tamanho, nota-se menor produção de massa seca da parte aérea e dos

Tabela 1. Concentração de açúcares totais não-estruturais (ATNE), sacarose, frutose, glicose e amido em tubérculos de S. aghensis analisados em diferentes épocas do ano. Médias \pm o desvio padrão seguidas de letras distintas diferem em $5 \%$ de significância pelo teste de Tukey $(P<0,05$ e $\mathrm{n}=6)$.

Table 1. Concentration of total non-structural sugars (TNS), sucrose, fructose, glucose and starch in tubers of S. aghensis examined in different seasons. Means \pm the standard deviation followed by different letters differ at $5 \%$ significance by Tukey test $(\mathrm{P}<0,05$ and $\mathrm{n}=6)$.

\begin{tabular}{clccccc}
\hline \multirow{2}{*}{ Data } & \multirow{2}{*}{ Estação } & \multicolumn{1}{c}{ ATNE } & Sacarose & Frutose & Glicose & Amido \\
\cline { 3 - 7 } & & & & $\mathrm{mg} \mathrm{g}^{-1} \mathrm{MS}$ & \\
\hline $30 / 04 / 2003$ & outono & $118 \pm 06,8 \mathrm{~b}$ & $062 \pm 03,2 \mathrm{~b}$ & $18 \pm 1,4 \mathrm{c}$ & $13,0 \pm 1,6 \mathrm{a}$ & $55 \pm 6,6 \mathrm{c}$ \\
$11 / 07 / 2003$ & inverno & $084 \pm 04,1 \mathrm{c}$ & $049 \pm 03,5 \mathrm{c}$ & $18 \pm 3,8 \mathrm{bc}$ & $5,0 \pm 1,1 \mathrm{~b}$ & $777 \pm 151,7 \mathrm{a}$ \\
$02 / 10 / 2003$ & primavera & $113 \pm 16,8 \mathrm{~b}$ & $088 \pm 15,1 \mathrm{~b}$ & $22 \pm 2,9 \mathrm{~b}$ & $0,6 \pm 0,1 \mathrm{c}$ & $66 \pm 15,8 \mathrm{c}$ \\
$29 / 01 / 2004$ & verão & $173 \pm 10,5 \mathrm{a}$ & $134 \pm 10,5 \mathrm{a}$ & $29 \pm 2,7 \mathrm{a}$ & $0,4 \pm 0,0 \mathrm{~d}$ & $86 \pm 13,2 \mathrm{~b}$ \\
\hline
\end{tabular}


tubérculos no outono. Maior produção de tubérculos ocorreu no inverno e da parte aérea, na primavera. Esses valores refletiram na baixa razão parte aérea:tubérculos no inverno (tabela 2). De maneira geral, os tubérculos de $S$. aghensis podem medir de 50 a $130 \mathrm{~g}$ MS. A produção de flores em todas as plantas amostradas (100\%) na primavera contribuiu para o aumento da razão parte aérea:tubérculo e para a diminuição na alocação de massa de tubérculo indicado pela fração de biomassa (tabela 2). Por outro lado, menor alocação de biomassa da parte aérea e maior alocação biomassa de tubérculos ocorreram no inverno. O conteúdo de água nas folhas (CAF) mostrou-se constante representando, em média, $86 \%$ da massa fresca. $O$ conteúdo de água nos tubérculos (CAT) apresentou variação sazonal, sendo os maiores valores encontrados no outono, primavera e verão (92\%) e um declínio no inverno (87\%) mostrando relação inversa entre os valores de precipitação (figura 2) e de amido (tabela 1).

Variações sazonais também foram observadas na concentração dos pigmentos fotossintéticos (tabela 3 ). As concentrações das clorofilas $a$ e $b$ foi maior na primavera e a maior razão clorofila $a: b$ foi verificada no inverno e verão. No inverno e verão, o teor de carotenóides foi maior, o que refletiu na menor razão clorofila total:carotenóides. Maior concentração de clorofila $a$ e $b$ foram registradas na primavera o que refletiu na maior razão entre os pigmentos clorofilianos e carotenóides.

Tabela 2. Valores referentes à massa seca $(\mathrm{g})$ total (Mstotal), da parte aérea (MSPa), dos tubérculos (MSTub), da razão parte aérea:tubérculo (PA:T), fração da massa da parte aérea (FMPa), fração de massa dos tubérculos (FMTub), porcentagem de plantas em floração (\%), conteúdo de água (\%) em folha (CAF) e em tubérculos (CAT) de S. aghensis. Médias \pm o desvio padrão seguidas de letras distintas diferem em 5\% de significância pelo teste de Tukey $(P<0,05$ e $\mathrm{n}=6)$.

Table 2. Values of total (TDMl), shoot (SDM), tubers (TDM) dry mass (g), the ratio shoot: tuber (S:T), fraction mass of shoot (MFS), fraction mass of tubers (FMT), percentage of plants in flower (\%), water content (\%) in leaf (WCL) and tubers (WAT) of S. aghensis. Means \pm the standard deviation followed by different letters differ at $5 \%$ significance by Tukey test $(P<0,05$ and $n=6)$.

\begin{tabular}{|c|c|c|c|c|c|c|c|c|c|c|}
\hline \multirow{2}{*}{ Data } & \multirow{2}{*}{ Estação } & MStotal & MSPa & MSTub & PA:T & FMPa & FMTub & Floração & $\mathrm{CAF}$ & CAT \\
\hline & & \multicolumn{4}{|c|}{ g MS } & \multicolumn{2}{|c|}{$\mathrm{g} \mathrm{g}^{-1} \mathrm{MS}$} & $\%$ & \multicolumn{2}{|c|}{$\% \mathrm{H}_{2} \mathrm{O}$} \\
\hline $30 / 04 / 2003$ & outono & $07,39 \pm 0,1 \mathrm{c}$ & $1,75 \pm 0,4 \mathrm{c}$ & $05,64 \pm 0,8 \mathrm{c}$ & $0,31 \pm 0,1 \mathrm{c}$ & $0,24 \pm 0,03 \mathrm{~b}$ & $0,76 \pm 0,07 \mathrm{c}$ & $000 \pm 0 b$ & $88 \pm 0,5 \mathrm{a}$ & $93 \pm 0,5 \mathrm{a}$ \\
\hline $11 / 07 / 2003$ & inverno & $23,26 \pm 0,1 \mathrm{c}$ & $3,98 \pm 0,6 b$ & $19,31 \pm 4,7 \mathrm{a}$ & $0,20 \pm 0,1 \mathrm{~d}$ & $0,17 \pm 0,05 \mathrm{c}$ & $0,83 \pm 0,06 \mathrm{c}$ & $000 \pm 0 \mathrm{~b}$ & $88 \pm 0,7 \mathrm{a}$ & $87 \pm 0,7 b$ \\
\hline $02 / 10 / 2003$ & primavera & $25,39 \pm 0,1 \mathrm{c}$ & $9,17 \pm 2,0 \mathrm{a}$ & $16,22 \pm 3,9 \mathrm{a}$ & $0,57 \pm 0,2 \mathrm{a}$ & $0,36 \pm 0,02 \mathrm{a}$ & $0,64 \pm 0,04 \mathrm{c}$ & $100 \pm 0 \mathrm{a}$ & $86 \pm 0,7 \mathrm{a}$ & $93 \pm 0,7 \mathrm{a}$ \\
\hline $29 / 01 / 2004$ & verão & $13,70 \pm 0,1 \mathrm{c}$ & $3,86 \pm 0,4 \mathrm{~b}$ & $09,84 \pm 3,2 \mathrm{~b}$ & $0,39 \pm 0,1 \mathrm{~b}$ & $0,28 \pm 0,03 \mathrm{~b}$ & $0,72 \pm 0,05 \mathrm{c}$ & $000 \pm 0 \mathrm{~b}$ & $85 \pm 0,5 \mathrm{a}$ & $92 \pm 0,5 \mathrm{a}$ \\
\hline
\end{tabular}

Tabela 3. Concentração de clorofila a (Cl. a), clorifila b (Cl. b), clorofila total (Cl. total), razão clorofila a:b (Cl. a:b), carotenóides (Carot.) e razão clorofila total:carotenóides (Cl:Carot.) em folhas de $S$. aghensis em diferentes épocas do ano. Médias \pm o desvio padrão seguidas de letras distintas diferem em 5\% de significância pelo teste de Tukey $(P<0,05$ e $n=6)$.

Table 3. Concentration of chlorophyll a (Chl. a), chlorophyll b (Chl. b), chlorophyll total (Chl. total), ratio of chlorophyll a: b (Chl. a: b), carotenoids (Carot.) and rate total chlorophyll: carotenoid (Chl: Carot.) in leaves of S. aghensis in different seasons. Means \pm the standard deviation followed by different letters differ at $5 \%$ significance by Tukey test $(\mathrm{P}<0.05$ and $\mathrm{n}=6)$.

\begin{tabular}{|c|c|c|c|c|c|c|c|}
\hline \multirow{2}{*}{ Data } & \multirow{2}{*}{ Estação } & Cl. a & Cl. b & Cl. a:b & Cl. total & Carot. & Cl.total:Carot. \\
\hline & & \multicolumn{6}{|c|}{$\mu \mathrm{mol} \mathrm{g}{ }^{-1} \mathrm{MF}$} \\
\hline $30 / 04 / 2003$ & outono & $4,15 \pm 0,51 \mathrm{~b}$ & $4,89 \pm 0,30 \mathrm{~b}$ & $0,84 \pm 0,36 \mathrm{~b}$ & $08,74 \pm 0,22 b$ & $1,25 \pm 0,43 \mathrm{~b}$ & $06,99 \pm 0,37 b$ \\
\hline $11 / 07 / 2003$ & inverno & $3,42 \pm 0,32 \mathrm{c}$ & $3,00 \pm 0,28 \mathrm{c}$ & $1,14 \pm 0,11 \mathrm{a}$ & $06,42 \pm 0,28 \mathrm{c}$ & $1,87 \pm 0,77 \mathrm{ab}$ & $03,43 \pm 0,71 \mathrm{c}$ \\
\hline $02 / 10 / 2003$ & primavera & $5,40 \pm 0,26 \mathrm{a}$ & $6,49 \pm 0,17 \mathrm{a}$ & $0,83 \pm 0,26 \mathrm{~b}$ & $11,89 \pm 0,35 \mathrm{a}$ & $1,06 \pm 0,76 \mathrm{~b}$ & $11,22 \pm 1,22 \mathrm{a}$ \\
\hline $29 / 01 / 2004$ & verão & $3,32 \pm 0,43 \mathrm{c}$ & $2,2,76 \pm 0,41 \mathrm{c}$ & $1,10 \pm 0,14 \mathrm{a}$ & $06,08 \pm 0,13 \mathrm{c}$ & $2,54 \pm 0,55 \mathrm{a}$ & $02,39 \pm 0,82 \mathrm{c}$ \\
\hline
\end{tabular}




\section{Discussão}

A concentração dos carboidratos em tubérculos de S. aghensis apresentou variação sazonal semelhante ao já relatado para algumas espécies de regiões temperadas e tropicais. De maneira geral, o teor de carboidratos totais solúveis não-estruturais tende a aumentar em herbáceas tuberosas (Carvalho \& Dietrich 1993, 1996, Dias-Tagliacozzo et al. 1999, Carvalho et al. 1997) e em gramíneas do cerrado nas estações do ano marcadas pela baixa precipitação (Moraes et al.2002). Comportamento similar também foi verificado nos diferentes órgãos vegetativos em arbóreas da floresta tropical do Panamá (Würth et al.2005). No entanto, semelhante a outras herbáceas como a Erica australis (Cruz \& Moreno 2001) e Oxytropis sericea (Wyka 1999) que se desenvolvem nos alpes do Mediterrâneo, S. aghensis mostrou aumento no teor de carboidratos de baixa massa molecular em detrimento do amido nos meses de maior precipitação.

Isso pode ocorrer devido a algumas razões. No caso de S. aghensis, a menor concentração de sacarose e glicose no inverno indica a mobilização desses compostos da parte aérea para a síntese de amido nos tubérculos $\left(\mathrm{r}^{2}=0,432, P<0,05\right)$ que aumentou acentuadamente de $\pm 8 \%$ da massa seca nas demais estações para $80 \%$ no inverno (tabela 1). Ainda, a menor concentração da sacarose e da glicose no inverno pode ser atribuída ao consumo energético dos tubérculos e a menor atividade fotossintética na estação seca, como verificado em algumas espécies nativas de biomas tropicais (Lemos Filho 2000, Franco et al. 2007). A redução da concentração de glicose após o inverno pode ser atribuída à demanda energética da fase de reprodução sexuada (tabela 2 ) e do crescimento vegetativo que ocorre, naturalmente, na primavera e verão, respectivamente, como sugerido para outras herbáceas tuberosas tropicais brasileiras (Carvalho \& Dietrich 1993, Isejima \& Figueiredo-Ribeiro 1993, Vieira \& Figueiredo-Ribeiro 1993, Cuzzuol et al. 2005). A maior concentração de sacarose e frutose no verão pode ser resultado da hidrólise de amido, ou ainda devido a translocação dos fotoassimilados para os tubérculos nos meses chuvosos devido às condições ambientais favoráveis à maior atividade fotossintética.

Tratando-se da flora brasileira nativa, este é o primeiro registro de variação sazonal de amido tão acentuada. Em outras regiões do planeta como a Ásia, também se verificou maior conteúdo de amido associado à menor precipitação em tubérculos de
Xanthosoma sagittifolium (Lu et al. 2005), mas não na magnitude verificada em $S$. aghensis.

Além da precipitação, variações periódicas da temperatura e umidade da atmosfera podem impor uma forte sazonalidade em importantes funções da planta como o acúmulo e mobilização de carboidratos (Cruz \& Moreno 2001, Rosa et al. 2004). No entanto, os valores de temperatura e da umidade relativa do ar da região estudada mostraram-se constantes em 2003, com ligeiro declínio no inverno (figura 1). Dessa maneira, estes fatores climáticos não poderiam influenciar significativamente no conteúdo dos carboidratos de S. aghensis ficando a variação sazonal dos açúcares de baixa massa molecular e do amido sob a influência direta das alterações da precipitação que apresentou maiores valores no outono, primavera e verão e, queda acentuada no inverno de 2004 na região da Grande Vitória. Algumas espécies revivescentes quando submetidas à restrição hídrica acumulam amido como parte da estratégia de sobrevivência (Stancato et al. 2001, Kamenetsky et al. 2005). Ao invés de amido, outras espécies tropicais da família Asteraceae (Carvalho \& Dietrich 1993, Dias-Tagliacozzo et al. 2004) e Amaranthaceae (Vieira \& Figueiredo-Ribeiro) do cerrado acumulam polissacarídeos do tipo frutanos no outono e inverno caracterizado pela restrição hídrica e baixa temperatura.

Além dos fatores ambientais, a fenologia tem expressiva influência no conteúdo das reservas energéticas. Conforme apresentado na tabela 1, a redução do conteúdo de amido na primavera coincidiu com a fase de reprodução sexuada o que refletiu no aumento da biomassa da parte aérea e da razão parte aérea:subterrânea (tabela 2). Mesmo assim, a biomassa total foi maior no inverno devido, provavelmente, ao aumento no teor de amido. Essas informações são confirmadas pela maior fração de biomassa de tubérculos e a menor fração de biomassa da parte aérea no inverno (tabela 2), representando maior alocação de carbono para os tubérculos quando sob influência da restrição hídrica.

$\mathrm{Na}$ primavera marcada pela floração, a inflorescência elevou a alocação de biomassa para a parte aérea. Resultados similares foram observados em plantas tuberosas do cerrado em diferentes fases fenológicas e sob influência de variáveis ambientais (Carvalho \& Dietrich 1993, 1996, Cuzzuol et al. 2005). Como já referendado amplamente na literatura, a fase de floração e de rebrota de herbáceas tropicais podem representar um consumo de até $40 \%$ das 
reservas energéticas (Carvalho \& Dietrich 1993, 1996, Cuzzuol et al. 2005).

Nas épocas do ano desfavoráveis ao crescimento como o outono e inverno, os carboidratos devem agir na proteção contra estresses exercendo a função de osmorreguladores (Chaves Filho \& StacciariniSeraphin 2001, Cruz \& Moreno 2001) por meio do ajustamento osmótico em resposta às variações ambientais (Sanchez et al. 1998). Nesse processo, moléculas orgânicas tais como açúcares álcoois e outros carboidratos poderiam aumentar a tolerância ao estresse hídrico contribuindo para o sucesso do estabelecimento de plantas em biomas que passam por algum tipo de restrição hídrica (Sanchez et al. 1998, Moraes et al. 2002). Além de osmorreguladores, os açúcares estabilizam proteínas e membranas substituindo a formação de pontes de hidrogênio com os resíduos de polipeptídios polares (Sanchez et al. 1998). No entanto, o acúmulo de carboidratos não solúveis, como o amido, configura-se como uma estratégia de reserva energética de $S$. aghensis durante a estação desfavorável ao crescimento. Na fase seguinte, a de reprodução, os polissacarídeos devem ter sido metabolizados para atender a demanda da fase de rebrota e da emissão de inflorescências dessa Gesneriaceae como ocorre em outras espécies acumuladoras de amido e de outros polissacarídeos de reserva (Carvalho \& Dietrich 1993, 1996, Cuzzuol et al. 2005, Kamenetsky et al. 2005, Lu et al. 2005). Desse modo, a tolerância de $S$. aghensis à restrição hídrica do inverno pode estar sob controle do metabolismo celular foliar como pode ser constatado pelos valores constantes do conteúdo de água foliar em todas as fases fenológicas e nas diferentes estações do ano (tabela 2). Portanto, a composição e variações nos metabólitos foliares podem revelar importantes informações a respeito dos mecanismos adaptativos de S. aghensis em resposta ao estresse hídrico. Nesse aspecto, folhas de algumas espécies que vivem em ambientes caracterizados pela restrição hídrica acumulam carboidratos de baixo peso molecular (Bohnert et al. 1995, Nelson et al. 1998, Sanchez et al. 1998, Moraes et al. 2002) e aminoácidos como a prolina e metionina, que funcionam como osmorreguladores (Szegletes et al. 2000, Subbarao et al. 2000, Carvalho 2005).

Além das alterações na composição de carboidratos não-estruturais, diferenças nos teores de clorofilas e carotenóides são comuns em plantas expostas ao estresse ambiental (Pessarakli 1997, Lemos Filho 2000, Franco et al. 2007). Isso pode ocorrer através da oxidação da clorofila e, conseqüentemente, causando a diminuição da razão clorofila:carotenóides pela restrição hídrica do inverno e pela alta radiação luminosa do verão como verificado em $S$. aghensis (tabela 4). Em algumas espécies tropicais a redução na eficiência fotossintética do FS II tem sido relacionada à elevada radiação (Joshi 1995, Hong \& Xu 1997, Franco et al. 2007).

As informações levantadas no presente trabalho permitem sugerir que $S$. aghensis seja uma espécie tolerante à baixa disponibilidade de água e que o aumento expressivo no conteúdo de amido na estação seca pode ser uma estratégia de armazenamento temporário de carboidratos uma vez que o metabolismo das plantas pode ser modificado, sensivelmente, pelas variações ambientais (Farrar et al. 2000, Geiger et al. 2000, Cruz \& Moreno 2001). No caso de $S$. aghensis o acúmulo de amido na estação seca, aliado à manutenção da parte aérea e a valores constante de CRA de folhas configuram-se em adaptações fisiológicas eficientes que permitem essa espécie desenvolver-se em ambientes rupestres, especialmente nos meses do ano caracterizados pela baixa precipitação.

\section{Agradecimentos}

À CAPES pela concessão da bolsa à primeira autora e à Profa. Dra. Lílian Beatriz Penteado Zaidan pela revisão e sugestões.

\section{Literatura citada}

Arnon, D.I. 1949. Copper enzymes in isolated chloroplast. Polyphenoloxidase in Beta vulgaris. Plant Physiology 24: $1-15$.

Bohnert, H.J., Nelson, D.E. \& Jensen, R.G. 1995. Adaptations to environmental stresses. Plant Cell 7: 1099-1111.

Carvalho, C.J.R. 2005. Respostas de plantas de Schizolobium amazonicum (S. parahyba var. amazonicum) e Schizolobium parahyba (Schizolobium parahybum) à deficiência hídrica. Revista Árvore 29: 907-914.

Carvalho, M.A.M \& Dietrich, S.M.C. 1993. Variation in fructan content in the undergound organs of Vernonia herbacea (Vell.) Rusby at different phenological phases. New Phytologist 123: 735-740.

Carvalho,M.A.M.\& Dietrich,S.M.C. 1996. Carbohydrates in tuberous roots of Coclospermum regium (Mart \& Schr.) Pilger at different stages of development. Revista Brasileira de Botânica 19: 127-131. 
Carvalho, M.A.M., Zaidan, L.B.P. \& Dietrich, S.M.C. 1997. Growth and fructan content of plants of Vernonia herbacea (Asteraceae) regenerated from rhizophores. New Phytologist 136: 153-161.

Chautems, A. 1991. A família Gesneriaceae na região cacaueira da Bahia, Brasil. Revista Brasileira de Botânica 14: 51-59.

Chautems, A. \& Weber, A. 1999. Shoot and Inflorescence Architecture in the Neotropical Genus Sinningia (Gesneriaceae). In: M.H. Kurmann \& A.R. Hemsley (eds.). The Evolution of Plant Architecture. Royal Botanic Gardens, Kew, pp. 305-322.

Chaves Filho J.T. \& Stacciarini-Seraphin, E. 2001. Alteração no potencial osmótico e teor de carboidratos solúveis em plantas jovens de lobeira (Solanum lycocarpum St.-Hil.) em resposta ao estresse hídrico. Revista Brasileira de Botânica 24: 199-204.

Clair-Maczuljatys, D., Sarthou, C. \& Bory,G. 1994. Effects of pruning on carbohydrate distribution in the trunk of sweet cherry (Punus avium L.). Scientia Horticulturae 59: 67-73.

Clippel, J.K. 2005. Conteúdo e variação sazonal de carboidratos na flora da Mata Atlântica do ES. Dissertação de Mestrado, Universidade Federal do Espírito Santo, Vitória.

Cruz, A. \& Moreno, J.M. 2001. Seasonal course of total non-structural carbohydrates in the lignotubers Mediterranean-type shrub Erica australis. Oecologia 128: 343-350.

Cuzzuol, G.R.F., Carvalho, M.A.M. \& Zaidan, L.B.P. 2005. Growth, photosynthate partitioning and fructan accumulation in plants of Vernonia herbacea (Vell.) Rusby under two nitrogen levels. Brazilian Journal of Plant Physiology 17: 401-410.

Dias-tagliacozzo, G.M., Figueiredo-Ribeiro, R.T.L., Carvalho, M.A.M. \& Dietrich, S.M.C. 1999. Fructan variation in the rhizophores of Vernonia herbacea (Vell.) Rusby, as influenced by temperature. Revista Brasileira de Botânica 22: 267-273.

Dias-Tagliacozzo, G.M., Itaya, N.M., Carvalho, M.A.M., Figueiredo-Ribeiro, R.T.L. \& Dietrich, S.M.C. 2004. Fructans and water suppression on intact and fragmented rhizophores of Vernonia herbacea. Brazilian Archives of Biology and Technology 47: 363-373.

Dubois, M., Gilles, K.A., Hamilton, J.K., Rebers, P.A. \& Smith, F. 1956. Colorimetric method for the determination of sugars and related substances. Analytical Chemistry 28: 350-356.

Farrar, J., Pollock, C. \& Gallagher, J. 2000. Sucrose and the integration in vascular plants. Plant Science 154: 1-11.

Franco, A.C., Matsubara, S. \& Orthen, B. 2007. Photoinhibition, carotenoid composition and the coregulation of photochemical and non-photochemical quenching in neotropical savanna trees. Tree Physiology 27: 717-725.

Geiger, R.D., Servaites, C.J. \& Fuchs, M.A. 2000. Role of starch in carbon translocation and partitioning at the plant level. Australian Journal of Plant Physiology 27: 571-582.

Hendry, G.A.F. \& Grime, J.P. 1993. Methods in Comparative Plant Ecology. Marcel Dekker, New York.

Hendry, G.A. \& Wallace, R.K. 1993. The Origin, Distribution and Evolutionary Significance of Fructans. In: M. Suzuki \& N.J. Chatterton (eds.). Science and Technology of Fructans. CRC Press, Boca Raton, pp.119-139.

Hoffmann, W.A., Orthen, B. \& Franco, A.C. 2004. Constraints to seedling success of savanna and forest tress across the savanna-forest boundary. Oecologia 140: 252-260.

Hong, S.S. \& Xu, D.Q. 1997. Difference in response of chlorophyll fluorescence parameters to strong light between wheat and soybean leaves. Chinese Science Bull 42: 684-689.

INMET. 2005. Instituto Nacional de Metereologia. http:// www.inmet.gov.br (acesso em 10.05.2007).

Isejima, E.M., Figueiredo-Ribeiro, R.C.L. \& Zaidan, L.B.P. 1991. Fructan composition in adventious tuberous roots of Viguiera discolor Baker (Asteraceae) as influenced by daylength. New Phytologist 119: 149-154.

Isejima, E.M. \& Figueiredo-Ribeiro, R.C.L. 1993. Fructan variations in tuberous roots of Viguiera discolor Baker (Asteraceae): the influence of phenology. Plant Cell Physiology 34: 723-727.

Jermyn, M.A. 1956. A new method for determination of ketohexoses in presence of aldohexoses. Nature 177: 38-39.

Joshi, S.C. 1995. Species specific diurnal changes in chlorophyll fluorescence in tropical deciduous and evergreen plants growing in the field during summer. Photosynthetica 31: 549-557.

Kamenetsky, R., Peterson, R.L., Melville, L.H., Machado, C.F. \& Bewley, J.D. 2005. Seasonal adaptations of the tuberous roots of Ranunculus asiaticus to desiccation and resurrection by changes in cell structure and protein content. New Phytologist 166: 193-204.

Lambers, H. \& Poorter, H. 1992. Inherent variation in growth rate between higher plants: a search for physiological causes and ecological consequences. Advances in Ecological Research 23: 187-261.

Lambers, J., Chapin, F.S. \& Pons, T.L. 1998. Plant Physiological Ecology. Springer-Verlag, New York.

Larcher, L. 2000. Ecofisiologia Vegetal. Rima, São Carlos.

Lemos Filho, J.P. 2000. Fotoinibição em três espécies do cerrado (Annona crassifolia, Eugenia dysenterica 
e Campomanesia adamantium ) na estação seca e na chuvosa. Revista Brasileira de Botanica 23: 45-50.

Lu, T., Chen, J., Lin, C.\& Chang, Y. 2005. Properties of starches from cocyam (Xanthosoma sagitifoliun) tubers planted in differents seasons. Food Chemistry 91: 69-77.

Marcelis, L.F.M. 1996. Sing strenght as a determinant of dry matter partitioning in the whole plant. Journal of Experimental Botany 47: 1281-1291.

McCready, R.M., Guggolz, J., Silveira, V. \& Owens, H.S. 1950. Determination of starch and amylose in vegetables: application to peas. Analytical Chemistry 22: 1156-1158.

Meirelles, S.T., Pivello, V. R. \& Joly, C.A. 1999. The vegetation of granite rock outcrops in Rio de Janeiro, Brazil, and the need for its protection. Environmental Conservation 26: 10-20.

Moraes, J.A.P.V.\& Prado, C.H.B.A. 1998. Photosynthesis and water relations in Cerrado vegetation. In: F.R. Scarano and A.C. Franco (eds.). Ecophysiological strategies of xerophytic and amphibius plants in the Neotropics. Oecologia Brasiliensis, v. 4. Universidade Federal do Rio de Janeiro, Rio de Janeiro, pp. 45-63

Moraes, M.G., Souza, A., Pessoni, R.A.B.\& FigueiredoRibeiro,R.C.L. 2002. Soluble carbohydrate similarities between Echinolaena inflexa and Melinis minutiflora (Poaceae). Hoehnea 29: 151-158.

Nelson, D.E., Rammesmayer, G. \& Bohnert, H.J. 1998. Regulation of cell-specific inositol metabolism and transport in plant salinity tolerance. Plant Cell 10: 753-764.

Pessarakli, M. 1997. Handbook of Photosynthesis. Marcel Dekker, New York.

Poorter, H. \& Nagel, O. 2000. The role of biomass allocation in the growth response of plants to different levels of light, $\mathrm{CO} 2$, nutrients and water: a quantitative review. Australian Journal of Plant Physiology 27: 595-607.

Riazi, A., Motsuda, K. \& Arslon, A. 1985. Water - stress induced changes in concentrations of prolines and other solutes in grower regions of young barley leaves. Journal of Experimental Botany 172: 1716-1725.

Rosa, M., Hilal, M., Gozalez, J.A. \& Prado, F.E. 2004. Changes in soluble carbohydrates and related enzymes induced by low temperature during early developmental stages of quinoa (Chenopodium chinoa) seedlings. Journal of Plant Physiology 161: 683-689.

Safford, H.D. \& Martinelli, D. 2000. Southeast Brazil. In: S. Porembski \& W. Barthlott (eds.). Inselbergs: Biotic diversity of isolated rock outcrops in tropical and temperate regions. Springer-Verlag, Berlin, pp. 339-389.

Sanchez, F. J., Manzanares, M., Andrés, E. F., Tenório, J. L. \& Ayerbe, L. 1998. Turgor maintenance, osmotic adjustment and soluble sugar and proline accumulation in 49 pea cultivars in response to water stress. Field Crops Research 59: 225-235.

Silva, F.A.S. \& Azevedo, C.A.V. 2007. A New Version of the Assistat-Statistical Assistance Software. World Congress on Computers in Agriculture, Orlando, pp. 393-396.

Stancato, G.C., Mazzafera,P. \& Buckeridge, M.S. 2001. Effect of a drought period on the mobilization on nonstructural carbohydrates, photosyntetic efficiency and water status in an epiphytic orchid. Plant Physiology and Biochemistry 39: 1009-1016.

Szegletes, Z., Erdei, L., Tari, I. \& Cseuz, L. 2000. Accumulation of osmoprotectants in wheat cultivars of different drought tolerance. Cereal Research Communications 28: 403-410.

Subbarao, G.V., Nam, N.H., Chauhan Y.S. \& Johansen, C. 2000. Osmotic adjustment, water relations and carbohydrate remobilization in pigeonpea under water stress. Journal of Plant Physiology 157: 651-659.

Thomaz,L.D.\& Monteiro, R. 1997. Composição florística da Mata Atlântica de encosta da Estação Biológica de Santa Lúcia, município de Santa Teresa-ES. Boletim do Museu de Biologia Mello Leitão 7: 3-48.

Vieira, C.C., \& Figueiredo-Ribeiro, R.C.L. 1993. Fructose-containing carbohydrates in the tuberous root of Gomphrena macrocephala St. Hil. (Amaranthaceae) and different phenological phase. Plant Cell \& Environment 19: 919-928.

Würth, M.K.R., Peláez-Riedl, S., Writht, S.J.\& Körner, C. 2005. Non-structural carbohydrate pools in a tropical forest. Oecologia 143: 11-24.

Wyka, T. 1999. Carbohydrate storage and use in alpine population of the perennial herb, Oxytropis sericea. Oecologia 120: 198-208. 